\title{
Non-Surgical Management of Iatrogenic Extrusion of Calcium Hydroxide Based Intracanal Medicament in Clinical Endodontics - A Case Report
}

\author{
Akshay Khandelwal ${ }^{1}$, Kavalipurapu Venkata Teja ${ }^{2}$, Jerry Jose ${ }^{3}$, Ajitha Palanivelu ${ }^{4}$ \\ 1, 2,3,4 Department of Conservative Dentistry \& Endodontics, Saveetha Dental College and Hospitals, \\ Saveetha Institute of Medical and Technical Sciences, Chennai, Tamil Nadu, India.
}

\section{INTRODUCTION}

Calcium hydroxide is used as an intracanal medicament in endodontics as it reduces intracanal microbial load and exudate discharge from infected teeth. Reports have shown that extrusion of calcium hydroxide periapically leads to an increased incidence of swelling, delayed periapical healing, nerve paraesthesia and other complications.

Teeth with immature apex or those undergoing apical resorption are prone to higher chances of periapical medicament extrusion, especially under high pressure delivery systems. This case report discusses nonsurgical management of periapically extruded non-setting calcium hydroxide by an innovative technique which is less invasive and comfortable both for the clinician and the patient.

Calcium hydroxide is widely used as an intracanal medicament for the treatment of pulpal and periapical diseases. ${ }^{1}$ The intracanal placement of calcium hydroxide can be done with a lentulospiral or a syringe-based delivery system. ${ }^{2}$ If extruded periapically, there is an increased incidence of swelling, delayed periapical healing, nerve paraesthesia and other complications. ${ }^{3}$ Case reports in the past have suggested surgical management of periapically extruded calcium hydroxide.

The purpose of this case report is to discuss an orthograde nonsurgical management of periapically extruded calcium hydroxide based intracanal medicament containing barium sulphate during endodontic treatment.

\section{PRESENTATION OF CASE}

A 26 - year - old male patient reported with swelling and pain in the upper front tooth. On clinical and radiographic examination (Fig.1 and Fig.2), 22 was diagnosed with Symptomatic Apical Periodontitis. The access cavity preparation was done using Endo Access Bur (Dentsply Maillefer, Ballaigues Switzerland) under rubber dam isolation and the working length was confirmed using digital radiograph (Fig.3 and Fig.4). The canal preparation was done using Protaper GOLD rotary files (Dentsply Maillefer, Ballaigues, USA) till F5 File, under copious irrigation with $3 \%$ sodium hypochlorite (Prime Dental, Maharashtra, India). The canals were dried using sterile paper points and calcium hydroxide - RC Cal (Prime Dental, Maharashtra, India) was introduced using pressure syringe system.

\author{
Corresponding Author: \\ Dr. Ajitha Palanivelu, \\ Department of Conservative and \\ Endodontics, Saveetha Dental College \\ and Hospitals, Saveetha Institute of \\ Medical and Technical Sciences, \\ 162, Poonamallee High Road, \\ Chennai - 600077, Tamil Nadu, India. \\ E-mail: ajitharijesh@gmail.com
}

DOI: $10.14260 /$ jemds/2021/583

How to Cite This Article:

Khandelwal A, Teja KV, Jose J, et al. Nonsurgical management of iatrogenic extrusion of calcium hydroxide based intracanal medicament in clinical endodontics - a case report. J Evolution Med Dent Sci 2021;10(33):2863-2866, DOI: 10.14260/jemds/2021/583

Submission 03-04-2021,

Peer Review 08-07-2021,

Acceptance 15-07-2021,

Published 16-08-2021.

Copyright (C) 2021 Akshay Khandelwal et al. This is an open access article distributed under Creative Commons Attribution License [Attribution 4.0 International (CC BY 4.0)] 


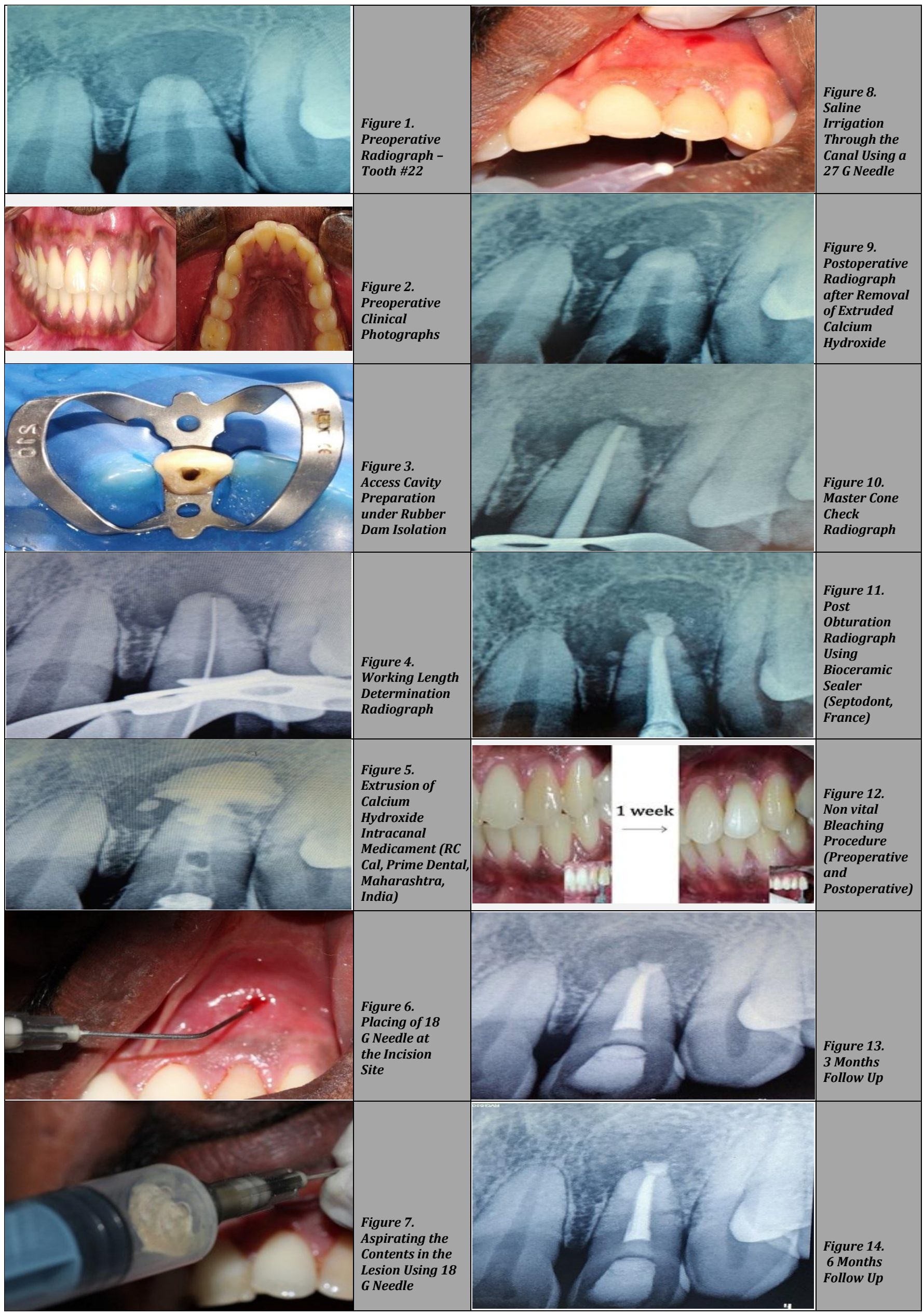




\section{DISCUSSION OF MANAGEMENT}

During the radiographic assessment of calcium hydroxide placement, it was noticed that the medicament had extruded into the periapical region beyond $3 \mathrm{~mm}$ (Fig.5). The temporary coronal seal was removed, and an orthograde approach was planned in an attempt to remove the extruded intracanal medicament non-surgically. The buccal cortical plate was palpated to locate the perforation, after which a vertical mucogingival incision was made distal to 22. Aspiration was done using an 18-gauge needle, yielding straw - coloured exudate and calcium hydroxide (Fig. 6 and Fig. 7). Saline irrigation was done using a 27-gauge needle and a $5 \mathrm{ml}$ barrel (Dispovan, New Delhi, India), through the access cavity preparation $1 \mathrm{~mm}$ beyond the apex (Fig. 8). When pressure was applied with syringe-based irrigation, the periapically extruded intracanal medicament was able to exit through the opening created on the buccal surface and the access cavity. This procedure allows debridement of the defect site without affecting the surrounding tissues.

A periapical radiograph was taken to confirm the removal of extruded calcium hydroxide (Fig. 9) and a closed calcium hydroxide dressing was given. The patient was prescribed ibuprofen $400 \mathrm{mg}$ and chlorhexidine mouthwash b.i.d for 3 days and was recalled after 1 week.

In the second appointment, it was noticed that the patient was asymptomatic and the incision site had completely healed. The temporary restoration was removed and the root canal was irrigated with $3 \%$ Sodium Hypochlorite solution and master cone was radiographically confirmed (Fig. 10). The canal was dried with paper points and coated with BioRoot RCS Bioceramic Sealer (Septodont, Saint - Maur - des - Fossés, France) using a lentulospiral (Dentsply Sirona, New York City, USA) and obturated with Gutta Percha (Diadent Group International, ChongJu City, Korea) using cold lateral compaction technique (Fig.11). The tooth discoloration was managed by non-vital bleaching using sodium perborate and composite restoration was done after a week. The patient was recalled at 3 and 6 months and was asymptomatic, demonstrating adequate radiographic periapical healing (Fig. 12 and Fig. 13).

\section{DISCUSSION}

RC Cal (Prime Dental) is a formulation of calcium hydroxide with barium sulphate, which gives the medicament its radiopacity. Though it has shown to be beneficial for the determination of calcium hydroxide placed in canal, its extrusion beyond the apex has significant side effects causing osteolysis. ${ }^{4}$ Vernieks and Messer et al. ${ }^{5}$ stated that extrusion of calcium hydroxide beyond apex compromises periapical healing. De Moor and De Witte et al. ${ }^{3}$ reported that barium sulphate has a negative effect on periapical healing. Histopathological reports suggest that calcium hydroxide in contact with periapical structures lead to lymphoplasmacytic infiltration and necrosis. ${ }^{6}$ Most case reports suggest surgical management of extruded intracanal medicament to facilitate periapical healing. ${ }^{7}$

The concept of the technique used in this report is a modification of surgical lavage ${ }^{8}$ and decompression techniques. ${ }^{9}$ The creation of an escape vent is an important aspect which allows removal of the extruded periapical material, during intracanal irrigation. This allows controlled exit of all the contents from the bony cavity and prevents their diffusion into the surrounding tissues.

BioRoot RCS is a bioceramic endodontic sealer which is biocompatible and possesses osteoinductive properties. ${ }^{10}$ It stimulates periodontal ligament fibroblast cells promoting periapical healing. ${ }^{10}$ This report demonstrated an increased rate of periapical healing, 3 and 6-month post - op.

\section{CONCLUSIONS}

During endodontic treatment, it is impervious for an operator to avoid iatrogenic accidents. Great caution should be taken during the use of premixed calcium hydroxide pressure syringe system, especially when the apical foramen is violated. This case report gives a novel technique for the management of iatrogenic periapical extrusion of intracanal medicament. This technique has significant advantages such as reduced patient discomfort, improved periapical healing and elimination of the need of surgical intervention.

Financial or other competing interests: None.

Disclosure forms provided by the authors are available with the full text of this article at jemds.com.

The authors certify that they have obtained appropriate patient consent form. In the form the patient has given his consent for his images and other clinical information to be reported in the journal. The patient understood that his names and initials will not be published, and due efforts will be made to conceal his identity, but anonymity cannot be guaranteed.

\section{REFERENCES}

[1] Athanassiadis B, Abbott P, Walsh L. The use of calcium hydroxide, antibiotics and biocides as antimicrobial medicaments in endodontics. Aust Dent J 2007;52(1 Suppl):S64-82.

[2] Peters CI, Koka RS, Highsmith S, et al. Calcium hydroxide dressings using different preparation and application modes: density and dissolution by simulated tissue pressure. Int Endod J 2005;38(12):889-95.

[3] De Moor RJG, De Witte AMJC. Periapical lesions accidentally filled with calcium hydroxide. Int Endod J 2002;35(11):946-58.

[4] Ingham E, Green TR, Stone MH, et al. Production of TNF- $\alpha$ and bone resorbing activity by macrophages in response to different types of bone cement particles. Biomaterials 2000;21(10):1005-13.

[5] Vernieks AA, Messer LB. Calcium hydroxide induced healing of periapical lesions: a study of 78 non-vital teeth. Int Endod J 1978;11(2):61-9.

[6] Leonardo MR, Da Silva LA, Leonardo RDT, et al. Histological evaluation of therapy using a calcium hydroxide dressing for teeth with incompletely formed apices and periapical lesions. J Endod 1993;19(7):348-52.

[7] Olsen JJ, Thorn JJ, Korsgaard N, et al. Nerve lesions following apical extrusion of non-setting calcium 
hydroxide: a systematic case review and report of two cases. J Craniomaxillofac Surg 2014;42(6):757-62.

[8] Hoen MM, Labounty GL, Strittmatter EJ. Conservative treatment of persistent periradicular lesions using aspiration and irrigation. J Endod 1990;16(4):182-6.
[9] Tian FC, Bergeron BE, Kalathingal S, et al. Management of large radicular lesions using decompression: a case series and review of the literature. J Endod 2019;45(5):651-9.

[10] Camps J, Jeanneau C, El Ayachi I, et al. Bioactivity of a calcium silicate-based endodontic cement (Bio Root RCS): interactions with human periodontal ligament cells in vitro. J Endod 2015;41(9):1469-73. 